\title{
A CLINICAL STUDY OF STATES OF "ECSTASY" OCCURRING IN AFFECTIVE DISORDERS
}

\author{
BY \\ E. W. ANDERSON \\ From the Cassel Hospital, Penshurst, Kent
}

(ReCeived 6TH DeCEMBer, 1937)

IN this paper four cases are recorded in which certain states of emotional exaltation occurred in the course of the illness. In three of these cases the state in question occurred as an interlude in a depression and in one following a hypomanic state. It is desirable to record these cases, first because of their relative rarity. Janet in 1903 (Les Obsessions, p. 380) had only seen half a score or so of such states ; Rümke (1924) found only nine in a series of nearly 5,000 admissions to the Amsterdam clinic, more than half of which were psychiatric cases ; and Paul Mondain (1933) states he had not seen one in four years of mental hospital practice. Secondly, it is desirable to point out the relationship of these cases to affective disorders. This term is used here to avoid the " straight-jacket" of manic-depressive psychosis. The relationship of ecstasies of the type described here, and possibly also many of the recorded cases of religious conversion, to such disorders is not explicit in the literature, although Janet after careful consideration finally rejects it and none of Rümke's cases was diagnosed as manic-depressive. Lastly, while the religious and mystical literature dealing with these conditions is enormous, that from the purely psychiatric angle is relatively scanty. Thus many text-books do not mention them at all and in others the reference is brief. The rarity of these conditions has led psychiatrists to fall back very largely on historical autobiographical descriptions.

First it is desirable to define the word " ecstasy," for the word enjoys no uniform meaning. Bleuler (1924) in his text-book states as follows : "States of rapture are designated as ecstasies. In such states association with the outer world is so completely interrupted that an absolute analgesia exists. The patients see the heavens open, associate with the saints, hear heavenly music, experience wonderful odours and tastes and an indescribable delight of distinct sexual colouring that pervades the entire body." He mentions their occurrence in schizophrenia. Bumke (1929) speaking of ecstasy says that the narrowing of consciousness which one attains in hypnosis shows analogies to ecstasy, that is, to the behaviour of those who are completely preoccupied with one idea of strong emotional tone and who proceed to put this idea into effect without any scruple, forgetting dangers, moral considerations, and the effects of their actions, 
but omitting nothing which could further the execution of their purpose (p. 135). Elsewhere he describes ecstatic states amongst epileptics in which they see the heavens open, hear God speaking to them, feel transfigured, or even feel themselves God (p. 642). This may probably be regarded as the classical psychiatric description of the state and is what is generally understood by the term " ecstasy."

Kleist (1928) has described an "Akute expansive Eingebungspsychose" in which an ecstatic state dominates the picture. Fundamentally these are similar states to those described here, but the two cases he quotes belong more to the " classical" psychotic ecstasies already mentioned. One of his patients spoke of having suddenly experienced an "enormous compassion" for the rest of humanity, of an endless love and goodwill, and declared himself willing to offer up his life for mankind. The other had a sudden revelation of the end of the world, felt himself blessed, and also wished to sacrifice his life for mankind. This patient also had visions. The ecstasy was followed by a hypochondriacal depression with anxiety. Kleist regards these cases as very closely related to chronic expansive paranoia with saviour and prophet delusions, and points out that religious preoccupation is commonly found in the premorbid personality and in the heredity. Kleist also believes that such cases are hereditarily closely related to the affective disorders, and also to epilepsy and epileptoid conditions. The states to be described below, however, present features commonly found in descriptions of religious conversion.

\section{Personal Cases}

CASE 1. Miss —, æ. 23 (Jewish).

Family History.-The elder of two children, brother aged 21. The mother suffered from fits of moodiness in earlier life, but is now more stable. A maternal aunt was described as " highly strung." A maternal uncle was odd, hypochrondriacal, and a crank. The father's sister had a breakdown, nature unknown, 20 years previously. The father was stable.

Personal History.-She was a healthy child, but was late in learning to walk. She had whooping cough, measles, and tonsillitis in childhood, otherwise no serious illness. She was a difficult child, bit her nails, and had nightmares. At school she was backward, had difficulty in learning to read and write. She was at several schools where she did not get on with the other girls and was removed by her mother. She disliked school intensely. Quite early she showed an aptitude for music and on leaving school commenced its serious study, but could never work consistently and failed to take her diploma. After six months' residence in France she could hardly speak a word of French. She was timid and shy. She conceived violent attachments to people and there was a history of a homosexual friendship, whose influence was still significant at the time of admission. For about two years before admission to hospital she had been on bad terms with her mother, to whom she was abusive. On account of her abnormal behaviour she was seen by a psychiatrist, who advised her removal from home. She stayed with a family, but there was friction and she could not get on with anybody. Finally she was referred to the Cassel Hospital.

Mental State on Admission.-She was elated and over-active, meddled in other people's affairs, and proved a nuisance. She was, however, good-natured, affectionate, and could be managed with firmness. There was no evidence of anything grossly psychotic, but there was a distinct paranoid component in the sense of mild ideas of reference-thought others were criticizing her, which was possibly true, and which in her 
case had in part a pathological basis in her sensitiveness. There were some obsessional features, such as extreme tidiness and exaggerated conscientiousness. She was troubled by silly phrases running through her mind, e.g. " to cater for a King." Her moods as described by her showed a definite alternation between depression and elation.

Soon after admission she became more calm, during which phase she had the experience described below. She said that she had had a kind of religious conversion. One day when working in the garden she suddenly felt " very uplifted "-an " ecstasy." She felt the world increased in beauty, everything was more real- " the beauty of reality. There wasn't any phantasy about it, the realization of all those things being more beautiful than I could conceive myself." She felt her ability for the task in hand was of the nature of an inspiration. At this time she saw two trees growing together, and this taught her a lesson that " one need be neither a martyr nor an aggressor." Since the ecstatic experience she had felt calmer. She spoke with God the whole time, " not an actual voice, but a knowledge of just exactly what to do." The ecstasy described lasted about six weeks with fluctuating intensity.

The state may now be described in greater detail. She said : "I just didn't mind anything; nothing mattered which anybody did to me, it didn't disturb me. I just felt at the time it was a right state to be in and that everybody ought to be in that state. I thought I was even going to become weller than even people who thought there was nothing the matter with them any way." In this state she felt she could convert an apparent disadvantage into an advantage. "The thing is that when I'm feeling miserable I think to myself, 'Is the whole thing a dream ?' I can't come to a true realization of my troubles. I'm absolutely certain it's wrong when people say it's too good to be true, for the happier I am the more I'm conscious it's real." (You said things seemed more in detail ?) "Well, they did seem in more detail because I was noticing more. One day I went into the wood and saw the individual grasses standing up ; there was no stagey scenery about it. Nothing that anybody could make would be like those grasses. There's so much picture-making in the world that people are inclined to look at a thing and say it's picturesque and see it on the flat side, instead of looking at it and saying it's very natural and very real. If people saw things actually as real as I saw them they wouldn't want a picture."

Alteration of time perception was present : "I just lived in the present without worrying about the past or ... the future. You absolutely have to be living in the present to get that feeling. I didn't care how long I was kept waiting for anything. I gave up thinking in time at all. I didn't watch the clock any more. It gave me more a sense of being than of doing." The feeling of being merged in the cosmos appeared in experiences like these : "You just have the feeling you're part of the earth, not a person on your own, sort of melt into it." (The whole earth ?) "It's a kind of sympathy and fellow feeling for all the things, trees and birds and everything, and a feeling of harmony, just part of it, there's nothing you could want more than that, certainly not at any time."

During the ecstasy her compulsive feelings disappeared or were modified. For instance, she still had a compulsion to do things "for her conscience' sake," but enjoyed doing them. She also enjoyed doing things for other people and felt friendlier towards everybody. It is to be noted that the ecstasy left behind it an alteration of the personality, a feeling that things were more real than they used to be ; but this disappeared when she was very depressed.

The state of ecstasy was replaced one evening by another which she described as follows : "I thought things had gone dead and the birds flying in the sky seemed dead, I thought things were worse than before, but I think it was just the ordinary way." She felt the " flickering back of time, sort of went back like this" and here made a sudden gesture.

Progress.-Her mental state reverted to that observed on admission and she showed, as before, fluctuations in mood. There was no recurrence of the ecstasy. 
A few months later she was discharged, but there was no fundamental improvement to record.

CASE 2. Miss —, æ2. 30.

Family History.-The father, a clergyman aged 65 years, was described as of " nervous temperament" and tending to worry over trifles. He suffers from diabetes mellitus. The mother, aged 64 , had a depression of religious colouring with self-reproach some years previously. The patient is the second of three-the other two are brothers, the younger of whom suffers from tuberculosis and at times becomes depressed and at others extravagant. One child by a former marriage of the mother appears to be healthy.

Personal History.-An eight-months child, she was delicate and did not talk properly until 5 years of age. At this time she wept if anybody spoke to her. She suffered from enuresis till 8 years of age, and had the usual exanthemata. Appendicectomy was performed at 12 years of age, and later the tonsils and adenoids were removed. Her periods were regular, but had been painful during the year before admission. The patient attended a High School and left at 16 years of age. She was evidently not scholastically brilliant, but good at games. About this time she had an attack of depression with depersonalization which shortly cleared up. She then took up ballroom dancing as a career and taught it for a few years, but gave it up because of ill-health, which from then on interfered almost continuously with her activities. At the age of 21 she developed symptoms of hyperthyroidism which yielded to treatment. Her first ecstatic experience occurred at this age following the "laying on of hands." She felt uplifted and experienced " perfect content, perfect peace." At 23 years of age she developed attacks of tetany, in association with hyperventilation of a psychogenic character. The present illness began three years ago, when she became "yellow and thin," had abdominal distension, nausea, anorexia and palpitation, and felt very weak. She became depressed and depersonalized-“" people seemed to be shadows, I didn't know where my voice was coming from, it didn't sound mine." After a few weeks' treatment in a nursing home she felt little improved. Soon after this the patient underwent a conversion experience while attending a High Church Mission. A few days later she made her first confession, after which she felt blessed. This was the beginning of a state she described as follows : "I just felt very peaceful and happy, very contented ; and I felt that every little thing I did, things that were ordinarily irksome, were a joy to do ; and because I loved God I felt He was in me and I felt I wanted to go out and tell the world about it. I didn't actually see a Cross, but I was always conscious of the Cross and from it came the most amazing love and power." The experience dominated her consciousness. She felt as if she had been born anew, and saw only good in others. Everything had increased beauty, and " everything seemed to speak of God. The Presence was real."

The above state came on abruptly, gradually increased in intensity, and remained so for about a year. During the period of ecstasy she had a love-affair with a married man. There was a certain amount of intimacy, though sexual intercourse was denied. She became depressed and developed much conflict and self-reproach over this affair, as it was contrary to her principles. The depression became intense, and at the same time the state of ecstasy disappeared. Gradually the depression cleared up. One year before admission she had a febrile illness diagnosed as influenza, with severe occipital headache, followed by a septic throat. After a slow recovery she took up social work. She felt, however, that she had returned to work too soon and began to feel " confused, and unable to concentrate." Depression and irritability set in and her gastric symptoms again became prominent. She again became "very thin and yellow" and had some depersonalization. There was a moderate pyrexia. On swallowing bismuth for an X-ray examination she had a psychogenic attack in which she went "cold and shivery" and lost the use of her legs and hands. An exhaustive physical examination proved negative. 
Mental State on Admission.--She seemed mildly depressed and a little listless. Beyond this, however, there was nothing grossly psychotic. She had neither delusions nor hallucinations. Her memory showed no impairment. She mixed well in the social life of the Hospital and presented nothing obviously striking in her behaviour.

It was evident at this time that she had already improved and a few weeks later she was discharged from hospital.

CASE 3. Miss —, æ. 27.

Family History.-The father, aged 83, was described as "nervous" and overanxious. The mother, aged 68, was pessimistic, prone to worry, afraid of going out, and suffered from nervous dyspepsia. The patient was the last of a family of six, besides one half-sister by the father's first marriage. The eldest of the six had a depression of religious colouring from which she recovered, but remained overanxious about her health and has still conflict and doubt in religious matters. The third sister at 15 years of age had impulses to do certain things and compulsive and blasphemous thoughts for a year. She now shows an exaggerated conscientiousness. The fourth, a brother, was unstable and drank heavily for a time, but has settled down satisfactorily. The fifth, a sister, has attacks of depression without obvious cause and is usually apathetic. A maternal aunt had " religious mania" and is subject to "fits of laughing and crying."

Personal History.-The patient was a healthy child, but had pneumonia when 3 months and rickets when 1 year old. About 15 years of age she developed a slight spinal curvature. She had influenza badly once or twice. Formerly she had headaches with nausea lasting a day. Catamenia commenced at 13 or 14 years, and were regular, but profuse and somewhat painful. At the periods she was either more depressed and irritable or more energetic. The patient attended a public school for two years, where she felt that she could never cope with anything, and was taken away by her mother because she was unhappy. She was then taught by a governess. Never trained to any employment, she has lived at home since leaving school. Her sister described her as unstable in mood, by turns happy and depressed, as being affected, and always acting a part. She showed a superficial versatility in music and writing and had mystical and religious interests. She had few friends and was very self-centred. She had several minor love affairs ; one important attachment of a pathological nature will be described in detail below. Masturbation and spontaneous orgasm on reading or seeing anything of sexual content had occurred on frequent occasions. The patient had always felt depressed and inadequate. About puberty her depression became more noticeable, and obsessional symptoms which had been present since early childhood became intensified ; for instance, when putting away any article she had used she was compelled to think of it in all its aspects and relationships and she also had a "délire de toucher." At 15 years of age she fell in love with a married man of lower social class. She knew this man by sight for three years before making his acquaintance, after which there was a good deal of intimacy, though sexual intercourse was denied. The man's wife found out this intimacy and protested to the patient's parents, who held very strict views. This proved the starting-point of her worst symptoms. After the rupture she was said to have "gone to pieces," slept badly, had fits of violence, and showed some hysterical behaviour, such as claiming falsely to have vomited blood. When the affair was broken off the patient stated that she passed into a state "like delirium." She recognized her surroundings, but could not describe them. She said " her whole personality seemed in disruption." This state gained in intensity, and at its height she acquired an abnormal power of detachment, though noticing every detail of her environment. "I seemed to be . . . watching myself." She also spoke of "a feeling of lightness and buoyancy, as if anything might happen." This lasted two days and was followed by a state of ecstasy of which she had three before admission. The first lasted from 
10th November to the end of December, 1931, the second the whole of February of the succeeding year, and again in the autumn of the same year for three months.

These states all presented similar features. She described the experience as follows : "I seem to merge into everything." There was " an intense consciousness of power and absolute ecstasy. I am awake all night if I happen to have it, sometimes it wakes me up. It comes in a sort of flood . . . over the body. A terrific consciousness of power in surges, like the sea coming against you." She also felt an excitement and palpitation, but added, "I feel calm as well. Things appear more real, as if you were just becoming alive and had never lived before. The whole being expands. If you are alone and you yield to it the more it grows over you, and you feel you can't keep on the ground. Everything is much more intense ; I notice everything I haven't seen before, lights and sounds." She felt as if she were in touch with God and felt she could "get at the back of everything." "You want to give yourself up to it because it seems as if something finally happened you would lose yourself, but it seems as if will seems to get in the way." She noticed a change in her perception of time. She had no sense of time, " everything is absolutely new, every minute is as if everything has just started." Time seemed to go quicker and she felt she had "all the time in the world to do things in." "I seem above time and yet it was intensified in some way. I could see time for what it was. It seemed like something which served a purpose, which was used to divide, to limit something, but not real." Yet her sense of everyday time was the same. "I seemed as much in the past and future as I was in the present, not only my own past and present but everything" (i.e. the whole of history). "It was the same with space, and to think of any place was almost as if I were there, I seemed so identified with it." In these states anything she wanted to know seemed answered, everything seemed natural, and she could see everything in its correct relationships. She felt also she had a sense of humour.

Her attitude towards her lover changed. She felt she could give up everything, that nothing had a hold on her any longer.

These states came without any warning and only when she felt " utterly to pieces," and she added that when she began to feel better in an ordinary way they disappeared like a tide going back. No heightening of sexual feeling was noted in the ecstasy. During the ecstasy her compulsive thinking disappeared and also her menstrual troubles. The condition "like a delirium" which preceded these ecstasies always followed them. Since the last ecstasy she had become progressively more depressed and complained of things " closing in on her." This state became intensified at times and after one such attack she had a phase of increased energy, which passed after a week or two. A few months before admission she became very weak and was finally admitted to Hospital.

Mental State on Admission.--She looked desperately serious, felt exhausted and rather sick, but denied feeling depressed. She complained of the obsessional symptoms mentioned. There was no evidence of delusions or hallucinations, though on two occasions some years previously she had heard a voice, once calling her name. She felt as if she were " possessed, bodily and mentally." Orientation and memory showed no impairment. She had a moderate grasp of general information and was tolerably intelligent. She had threatened suicide on several occasions, but had made no attempt.

Progress.-Her condition remained more or less stationary, but she showed fluctuations in mood and was sometimes very depressed. At times she felt she was losing her personality and became identified with people she met. She had to be by herself for a time before she felt she recovered her own identity. At times also she felt herself merging into objects, for example, she felt she was becoming one with the chair on which she sat. She felt "fluid" and that the substance of inanimate things was alive. At times also she felt her hands became larger. She felt "miles away" from her surroundings and objects appeared very small "like doll's house things." Sometimes she felt she was growing smaller and "dwindling." 
On 4th July, 1937, she had another ecstasy which she described as follows : "A stillness gradually came over my whole being and a sense of expectancy impossible to put into words. ... There seemed a trembling vibration over my consciousness, a veil between me and what I should know, as if I were hovering beyond a great mystery. Then a dawning sense of exquisite harmony, without being lifted into the first state of ecstasy. . . . Thought, space, and time dropped away. . . ."

This experience occurred at 11.30 p.m., came suddenly like its predecessors, and lasted for about half an hour. She did not report it until the next morning. She was then calmer and felt " more normal." On the morning of the 5th she said : "I feel as if my thoughts and worries are gone." She perceived a sense of "harmony and rhythm" not only in herself but in everything else like " a flowing" : " it seems as if everything's flowing and I'm in it." She also felt a little abstracted, which she had not felt in the more intense form of the experience. This ecstasy differed in some respects from its predecessors : " a sense of it without being in it." She felt "partly depressed," which she believed was because the ecstasy was not as intense and complete as its predecessors. She had, however, even in this brief experience felt herself at one with the universe, but not to such a degree as before, and it was experienced less as " merging" than as a sense of harmony. In this state she also had a feeling of strength which persisted to the following day. In her own words "the other ecstasy was an overwhelming sense of happiness, this time I feel more calm and have not the same sense of activity." When seen the day after there was outwardly no change in her, certainly no objective increase of activity. She described a change in her thinking. Before the ecstasy she had " a rapid flow of thought." When the ecstasy supervened it seemed " as if the thoughts flowed away" and left her with a sense of stillness. The rhythm of her thinking and the rhythm of the whole environment coincided. The next morning she still had the sense of immensity which she experienced in all her ecstasies. The patient has always been preoccupied with the question of what a normal state is like. She thought that in the normal individual this harmony between him and his surroundings existed without his being conscious of it, and it was just this consciousness which differentiated the ecstasy from the normal.

On the 7th the patient again felt depressed and "panicky" and was " oppressed by a sense of guilt," but again the same evening she stated as follows : "I had a sense of that state without being in it. I felt happier-in harmony-at rest without being overwhelmingly conscious of it ; feeling as if the mind and body are more harmonized." The recent occurrence of an ecstasy seemed to have enabled her to analyse her experience better. The difference in the "merging" in the ecstasy is that in this state it seems as though everything were coming into her, associated with a feeling of forward motion, "something calming and then a sense of everything moving into me." In her depressed state " as if I'm being dragged back and dissolving mentally and physically and outside all motion." The patient vouchsafed the information that in the ecstasy everything inanimate seems to be moving and added "motion seems to give the object its form. Before this everything seemed separate, there was nothing binding it together." In the depressed phase " motion seemed to be lessening and hadn't any existence. I could see the things, but I was outside the consciousness of any sort of life at all, an abyss. . . . It seemed as if there never was and never could be any sort of motion at all."

Since this ecstasy her mental state has reverted to what it was before.

CASE 4. Mrs. —, æ. 39 years.

Family History.-The father, who died, aged 53, from phthisis, was described as very conscientious. The mother is alive, aged 58, happy-go-lucky, cheerful, and rather dependent. The patient is the eldest of four, the other three being normal. The paternal grandfather drank heavily. Beyond this the family history was essentially negative.

Personal History.-The patient was a healthy child and developed normally. There 
was no history of neuropathic traits. Beyond childish ailments she had no serious illness until 16 years of age, when she had a brief attack of depression. At this time she became interested in religion, which interest has continued, though less strong. She had a high-school education until aged 17 years. Her school record was good; she played games well and had no difficulties. On leaving school she taught for a time and then took up nursing, which she had to give up because of " adhesions " following appendicectomy and removal of an ovarian cyst at 18. For a few days previous to her periods, which were regular, she was depressed.

She was ordinarily cheerful and sociable, though she worried and took the troubles of others to heart. Her mood fluctuated. She had many interests and read widely. At 23 years of age she married a man some years older and had two children and between them a still-birth. The marriage was not particularly happy. She had a pelvic repair operation a year after her first confinement and later an amputation of the cervix. Her last delivery was by Cæsarean section. Four years before admission she had an attack of pleurisy, from which she slowly recovered. She became depressed and developed a sobbing breathing. She remained depressed for two years or so, during which she was treated by psychotherapy. Improvement took place until the onset of the present illness at Christmas 1934. She began to feel run-down and developed influenza complicated by an otitis media, three months later phlebitis with low fever set in. Serious chronic illness was suspected, but excluded. She complained of lack of energy, became depressed, and felt she "wanted to get out of it." For this disturbance she was admitted to the Cassel Hospital.

Mental State on Admission.-She was slightly depressed, was self-reproachful over a recent sexual episode, and complained of a " mental tiredness." There were no delusions nor hallucinations. Orientation and memory were unimpaired. Her intelligence was above average. At times the difficulty in breathing reappeared, always in relation to an unpleasant event.

After four months in Hospital, during which her condition slowly improved, she passed abruptly into a state which she described as follows : "The first and most persistent impression was one of great tranquillity and freedom from anxiety and an underlying conviction that this condition was unassailable. I was very remote from my natural surroundings and the entrance of people was a nuisance, as I had to pull myself away from the realms of bliss and make some effort to cope with facts which seemed unreal. People did not disturb the state except in so far as it meant coming out of it temporarily. They seemed vaguely unreal and it was I who was real. An international event of some importance which occurred while I was in that state floated into my mind now and then in such a way as to make me think I had dreamt it. Gradually there crept into the sensation of tranquillity a vivid impression of sunshine and summer at its best. I wandered or rather floated in flowered meadows and gardens. The thought now and then was, "This must be where the idea of the Elysian Fields originated.' All the sensations of a perfect summer's day were present, the hum of the bees and the clear brilliance of the atmosphere. As I dislike the really hot weather it was evidently early summer, as the feeling was of perfection. The flowers were many and perfect-almost artificial in their perfection, and the fruit also. The colours were violent, almost crude, and it was almost as if everything had had a coat of varnish. I was quite alone in these wanderings and there was never an impression of anyone else being present. Time passed quickly and I was unconscious of its passage. Periodically, say at meal-times, I looked out of the window to assure myself that the trees were leafless, and metaphorically ' pinched myself' to see if I were awake. This condition lasted for six days, diminishing towards the end." During this experience she was outwardly calm and unperturbed. A few weeks later she was discharged improved. 


\section{Discussion}

\section{Views on the Nature of States of Ecstasy}

The states described by the first three patients correspond to the phenomenon designated by R. M. Bucke as " cosmic consciousness." Bucke had himself undergone an experience which he described as follows : " The prime characteristic of cosmic consciousness is a consciousness of the cosmos, that is, of the life and order of the Universe. Along with the consciousness of the cosmos there occurs an intellectual enlightenment which alone would place the individual on a new plane of existence-would make him almost a member of a new species. To this is added a state of moral exaltation, an indescribable feeling of elevation, elation, and joyousness and a quickening of the moral sense, which is fully as striking and more important than is the enhanced intellectual power. With these come what may be called a sense of immortality, a consciousness of eternal life, not a conviction that he shall have this, but the consciousness that he has it already."

Elsewhere he says : “I was in a state of quiet almost passive enjoyment, not actually thinking but letting ideas, images, and emotions flow of themselves, as it were, through my mind. All at once . . . I found myself wrapped in a flame-coloured cloud. . . . Directly afterwards there came upon me a sense of exaltation, of immense joyousness accompanied or immediately followed by an intellectual illumination impossible to describe." (Quoted by James, 1908, p. 398-9.)

This state only lasted a few seconds. Edward Carpenter, who had a similar experience, regarded it as a third and highest state of consciousness, differentiated from the simple consciousness of very young children and primitive men and the self-consciousness or consciousness as we ordinarily understand it in normal adults. In the stage of " cosmic consciousness," he says, " the object suddenly is seen, is felt to be one with the self. . . . This form of consciousness is the only true knowledge-it is the only true existence . . . in which the subject and the object are felt to be parts of the same being, of the same including self of all."

Experiences of a like character have been recorded by mystics of every religion. Crichton-Browne (1895) described under the title of "dreamy mental states" a group of depersonalization phenomena which he related chiefly to epilepsy. He also mentioned the states with which we are concerned and quoted a passage from J. A. Symonds, who described his experience. CrichtonBrowne says this writer was " haunted by melancholy" throughout his life. James (1908, p. 380) set up four criteria of the mystical ecstatic state, namely " ineffability," " noetic quality," " transiency," and " passivity." He regarded the first two as the most important and constant. By " noetic quality" he meant that perception of increased and hitherto unguessed meaning in things, for he stated " they are states of insight into depths of truth unplumbed by the discursive intellect. They are illuminations, revelations, full of significance and importance. ..." He believed that mystical states were not long sustained and regarded an hour or two as the limit. With regard to the last quality 
James (1908) stated that the mystic " feels as if his own will were in abeyance and indeed sometimes as if he were grasped and held by a superior power." Mayer-Gross (1914) differentiated two types of emotional experience, which he designated "Glücksrausch" and "Glücksaffekt." He set up differential criteria, one of which was that in the former the subject was given over entirely to the emotion to the displacement of other objects of consciousness associated with a more or less complete passivity, whereas in the latter there was an intensification of the ego associated with an urge to action and a feeling of increased capacity. Whether these two states can always be so clearly differentiated is doubtful, and the cases given here present features of both. Janet (1926-28) observed a patient over a number of years in the course of whose illness ecstatic interludes occurred. The ecstasies of this patient corresponded closely with the classical descriptions of the state. Janet distinguished three degrees in the ecstasy, which he designated " recueillements, extases, and ravissements" (p. 45). He noted the complete suppression of motor activity in his patient, the feeling of a "sort of possession," the sense of certitude, of internal peace and power, and the feeling of ability to solve all problems and answer all questions. His patient also described the great " luminosity " of her visions. He gives as the essential criteria of the ecstasy state the complete immobility and detachment from outside things, the enormous internal activity, the intense faith in the reality of what is experienced, the profound feeling of automatism and inspiration, and the special feeling of joy (p. 137). Janet also regarded what he called the "sentiment du divin" (p. 127) as essential and stated : "The true ecstasies are the religious ecstasies."

Gruhle (1922) stated that there were only two conditions, true epilepsy and schizophrenia, in which such states of ecstasy supervene without the assistance of inner or outer agents. He stressed the qualitatively abnormal feeling in ecstasy and said that the feeling of joy was more than a heightening of the normal feeling of happiness and that the essential feature was the peculiar linking of feeling with knowledge. He mentioned the frequent occurrence of such states as a precursor of an epileptic fit. Further, he wrote that the states of bliss which occur in schizophrenia could not be qualitatively differentiated from those in epilepsy, and mentioned the visual hallucinations and heavenly manifestations occurring in each. He gave examples of the different forms of ecstasy, including those following the so-called spiritual exercises of the Buddhists and the ecstasies produced by intoxicants such as mescal and opium. Jaspers (1923) recognized the wide range of degrees of intensity, from purely sensuous feelings of joy to the religious mystical states. He mentioned that "sublime feelings" occur phasically in psychasthenics, but the more intense ecstatic states characterized by a feeling of grace and blessedness together with the perception of heightened significance in things in schizophrenics. Flournoy (1915) described a woman who experienced typical ecstatic states. This patient showed a marked dissociative tendency, as shown by automatic writing, clairvoyance, etc., evidence of that peculiarity of the ego (Ichlähmung) which is responsible for similar phenomena such as glossolalia and possession and is an important factor in the psychopathology of the states under discussion. 
Rümke (1924) found clinical features similar to those in the present material in his cases. He devotes little consideration to the time-disorder, which is not prominent in his material. He finds the difference between these states and those of mania to consist in the alertness and greater superficiality of the manic, whose disorder he relates to a less profound disturbance of the ego. He regards a state of inner tranquillity as one essential factor in the causation of these conditions. He found that these states occur principally in complicated psychoses, which is in agreement with my own observations. His cases, however, were all much more severe than mine. He regarded the syndrome as prognostically favourable, apart from the clinical diagnosis of the case as a whole, a remarkable statement which finds no support from the present study. In agreement with Janet he found religious feeling an essential part of the state. He was unable to find a causal explanation of the condition in the preceding state, and noted a contrast between the state of bliss and its precursor. He found that a motivating factor played a very small part in the genesis of these states. He found that this syndrome occurred seldom or never in manicdepressive psychosis. Rümke bases his study on the psychology of Scheler and finds a confirmation of the latter's views. Rümke regards the conditions discussed here as belonging to the category of the "Geistige Gefühle" which involve the very core of the personality.

Psychoanalytic writings on ecstasy are few. Glover, in a hitherto unpublished paper on "Idealization," speaks of the tendency in some patients to excessive idealization of their natural surroundings. It is not clear, however, whether his " idealization" corresponds entirely to the states described here, and he gives no description of similar prolonged states of ecstasy. Alexander (1931) described the Buddhist path of initiation and saw in it a reversal of the normal psychic development as conceived by the psychoanalytical school. $\mathrm{He}$ claimed to recognize in it the catatonic ecstasy of schizophrenia. Thouless (1923), speaking of " mystical conversion," states : "It is not only that part of the libido specialized in the sex-instinct that is sublimated, but the whole of the libido employed in the activities and affections of this world life." Geiger (1911), in an analysis of æsthetic appreciation, has shown that in one form the "Einfühlende Einstellung," a union of the ego with the object, occurs. He showed that the process involved an activity on the part of the observer's ego which is lacking in the conditions described here, where the ecstasy appeared without any conscious striving. It is evident, however, that the same essential psychological phenomenon occurs in both cases, and it may be that some few individuals actually experience a type of ecstasy in the contemplation of artistic works, more particularly of music. Lastly, Zucker (1934) regards the Shamanistic experience as a " participation " experience, as Lévy-Bruhl terms it (p. 344), that is, a state of consciousness in which the sense of duality of subject and object is abolished. The subject is at the same time aware of his own identity yet feels himself identified with the object. Zucker continues: "In this experienced unification of subject and object, in this 'veritable possession' where the psychic state of interrogation and the will to answer coincide, lies the possibility of a liberation and a satisfaction of both." Zucker says the answer is experienced 
intuitively (erlebt), not logically deduced. It is clear that we are dealing here with a psychic state closely corresponding to if not identical with ecstasy.

A review of the literature demonstrates thus : the comparative rarity of these states, the existence of different types of "ecstasy," and the frequent statement that they are common in schizophrenia, epilepsy, and hysteria. Their occurrence as a phase of manic-depressive illness is not mentioned. Psychopathologically these states are characterized by a peculiar feeling of joy (Glücksgefühl) consisting of a remarkable blend of feeling with knowledge. The amount of psychiatric attention, however, which they have so far received is slight, and it is clear that the whole field requires more study, particularly perhaps the relationship between these states and other emotional states occurring in the realm of the normal.

\section{Features of Personal Cases}

A calmness and tranquillity was reported by all the patients, and in the first case was associated with a definite decline in motor activity noticeable after the previous hypomanic state. None of the cases showed the complete immobility of Janet's patient. Passivity, associated with a feeling of "merging" into external reality, was most noticeable in the first and third patients, whilst the second spoke of God as " being within her." The fourth subject differed in that the external reality seemed less real, as in depersonalization, whilst the ego was experienced with a heightened reality. Also there was no merging with external reality, although the feeling of passivity was present. This sense of the self as the only reality was also experienced by Symonds, who wrote : "At last nothing remained but pure absolute abstract self. The universe became without form and void of content. But self persisted formidable in its vivid keenness . . ." (quoted James, 1908). This experience is not quite the same as that of the fourth patient, who had no sense of impending dissolution of identity.

The feeling of being amidst unseasonably beautiful surroundings, constituting a kind of extension of the " ego" and separating the patient from the outer world, which she always felt was intrusive, was not hallucinosis. Janet's patient also saw the outside world transformed at times in a similar way. In cases 3 and 4 the passivity was clearly experienced in terms of volition. The state of passivity receded in the third patient whenever her will asserted itself, and in the fourth patient diminished in intensity whenever she had to bring herself back to earth.

The feeling of merging with the environment described by some of the patients is, however, not peculiar to ecstasy alone. The third patient experienced it while in a depressed state, but in a different way. In the ecstasy the feeling of "merging " gave her a sense of gain : " as if I found myself and everything else." In the depressed state she lost herself : "I feel my thoughts go and as if I shouldn't be able to move, as if I were sinking into something." In the ecstasy she had a greater sense of identity, the lack of which feeling was usually a constant and prominent complaint. For her the ecstasy consisted of 
a sense of union with separateness. She further spontaneously divided the ecstasy into three stages, first a feeling of immensity, secondly a feeling of " terrific activity" behind each object, as if everything seemed moving and she were moving with it, which was finally followed by a feeling of " being centred on something." During this phase her thoughts were " terrifically active," a " sort of terrific calm and yet active." She was conscious, however, of no pressure of thought. It is interesting to note that in contrast to the relative decrease of motor activity of the first patient during the ecstasy, this patient became more active, although after the last ecstasy her sense of activity was diminished.

The change in the external world was a noticeable feature in all four subjects. The first three patients observed that everything seemed more beautiful as well as more real, and more intense, that details were perceived which had not been noticed before. The first patient saw " the individual grasses standing up." With regard to the "sentiment du divin," the first and the third patients, in contrast to the second and fourth, were not strongly religious before the ecstasy. Both, however, experienced the nearness of or rather the identification with God. It appears therefore that a strongly religious bias is not essential even to the content of the ecstasy. One must, however, agree in general with Janet when he says : "Les idées et les sentiments religieuses font partie de la définition de l'extase complète," with this qualification, that if by this is meant that the subjects become aware of the nearness of, or more properly identify themselves with an immense cosmic power at first outside themselves, then this may be accepted as an essential feature, though undoubtedly there are some types of ecstasy or ecstasy-like states, as that of the fourth patient, where this feeling, despite a definite previous religious attitude, did not occur. The fourth case, however, is atypical. It is to be expected that the religious beliefs of the subject will exert an influence on the content of the ecstasy.

The experiences of these patients are paralleled by others of which many historical biographical instances have been recorded, the details being remarkably constant from case to case. In abstracting common features, some variance with other authors arises. To take James's criteria, the lack of descriptive ability is certainly a common feature. It also occurs in a large number of pathological mental states and only appears striking here because of the strong urge to communicate these emotions. The passivity of the subject is one of the most striking and essential features. Such ecstatic states may last for a long time, up to a year. The " noetic quality" emerges clearly. Janet stresses immobility as an essential feature, but this was not characteristic of the cases recorded here.

\section{Disorder of Perception of Time and Environment}

One constant feature in these cases is the alteration in perception of time. The third patient was conscious of the purely arbitrary and practical value of mathematical time which she also felt went more quickly. She stated : "I didn't feel limited by it (time). I felt it was something I was using, not some- 
thing which existed." The feeling of being one with the cosmos is well expressed by the statement of the third patient, that she seemed as much in the past and the future as she was in the present, not only her own past and future, but the past and future of everything. She felt that past and future telescoped to a point, the present. The first patient said, "I just lived in the present without worrying about the past or . . future"; the second patient felt " born anew "; the third felt " as if everything had just started," as " if she had never lived before"; and the fourth patient felt that time passed quickly. This is in contrast to the experience of time in some cases of depersonalization, in which time becomes a dreary eternity for the patient. In depersonalization the past is perceived at times as almost endless, whilst the future seems remote, which Janet regards as typical of this state. The feeling of being reborn occurs repeatedly in other descriptions of these states, and is regarded as the central point of the conversion experience. It is also, of course, common in schizophrenia. Janet and Flouroy also noticed the change in time perception in their patients. Janet's patient no longer distinguished the past from the present, and Flouroy's patient felt that she had plunged into eternity.

In ecstasy these subjects live entirely in the glorious present, which, as it represents perfection, requires no count to be taken of the past with its failures nor the future with its hopes and expectations. They have attained that beyond which there is nothing better. Or it may be said that the present is so real and claims their attention so exclusively that past and future have no significance. Janet considers that this transformation of time is brought about by the indifference to external action, as in his patient, but this explanation does not hold in the case of the third patient, who, as we have seen, became more active externally. Of the sense of duration he says elsewhere that the "sentiment d'effort spécial " engenders all our ideas of time (1926-28, II, p. 611). In ecstasy, where everything seems effortless or nearly so, time is experienced as passing quickly.

Similarly the change in the environment both in these patients and in other recorded instances is constantly expressed. Also they speak of the greater beauty of everything and the greater feeling of friendliness and sympathy for others, which was most striking in the first patient, in whom the paranoid attitude completely disappeared.

The feeling of buoyancy and lightness experienced by the first patient is also mentioned in an example by R. W. Trine, who says of his subject : " this spirit of infinite peace so takes hold of and so fills him, that it seems as if his feet could hardly keep to the pavement, so buoyant and exhilarated does he become by reason of this inflowing tide " (quoted James, 1908). This subject and the third patient both speak of the experience as of a " tide." Janet's patient had similar experiences.

The memory which the subject retains of the experience and its subsequent effect on the personality must be considered. Practically all authors are agreed as to the vivid memory retained of these states. This is equally noticeable in the cases presented, as some of the descriptions were given after the experience. It would be remarkable if such an experience did not make an indelible im- 
pression. It would appear that the personality of the third patient is little modified by the experience. To her it simply remains a remarkable and abnormal experience. Though stress is laid in the religious writings on the spiritual value of such an experience, it has not meant anything of the kind to this patient, nor has it modified her conduct. For a change in conduct to result the subject must be strongly religious or else have a desire for faith. This religious preoccupation need not be entirely conscious, as James points out $(1908$, p. $230 \mathrm{ff}$.), but if it is present at all, the ecstasy experience results in a fusion of conflicting elements in the personality, which remains more or less permanently modified by it. The intensity of the ecstasy experience in itself would not appear to be sufficient to induce this modification of the personality. This feeling of merging with a greater power outside the subject, however, is usually interpreted as union with " God" or universal spirit.

It seems probable that the impression on the first patient was more profound and remained with her as a glimpse of perfection, except when she became extremely depressed. It is doubtful if the experience had any essential influence on her conduct. In the second case the ecstasy became a true conversion experience of which the religious background was a vital factor. It is interesting to note the different valuation which the second patient gave to the two states, the ecstasy and the subsequent depression. The former was a spiritual experience, a revelation of the Holy Spirit, and was regarded as healthy if unusual ; the latter as illness and a just reward for her backsliding. The fourth patient regarded it as merely an odd and rather amusing experience, in spite of a religious bias, which did not suffice to make her interpret it in terms of a divine experience. As already mentioned, however, this was not a typical ecstasy, and the feeling of merging with the cosmos was absent. This exhilarating experience is differently evaluated according to the individual personality.

\section{Summary of Features of Personal Cases}

Four cases have been recorded in which a special feeling of joy, a component of which was a sense of calmness, was experienced, associated with an alteration of consciousness which is typical of the states under consideration. This change involved an altered experience of the ego described as a feeling of merging with the cosmos or with God, although the personal identity did not become lost, but was rather intensified, particularly in one case, in striking contrast to her usual state. A change in time perception was also noted. The mood, the change in the experience of the ego, and the time-disorder were constant. The fourth case presented unusual features. The subjects retained a vivid memory of the states which in two cases effected a change in the subsequent personality of the patient. 


\section{D iagnostic Considerations}

The first patient was an outspoken manic-depressive with obsessional and paranoid traits, with frequent hypomanic alternating with depressive phases, and with one ecstatic period. Hysterical features were not evident, though she tended to magnify her symptoms in order to obtain notice. This feature is of doubtful importance, as there were certainly no hysterical features similar to those in the other cases. The second case was one of recurrent depression with ecstatic phases and isolated hysterical conversion features. She had not a typical hysterical personality. She seemed in fact to be a serious and conscientious person. The third case was one of depression with ecstatic phases, with obsessional features and hysterical tinge. The fourth case was also one of recurrent depression, with one typical ecstatic interlude and occasional hysterical conversion features. The diagnosis in each case was based first on the family history, secondly on the previous personality, and in two cases on the occurrence of previous more or less circumscribed depressive attacks. Lastly the mental state during the present illness was taken into consideration. The family history in cases 1,2 , and 3 shows similar disorders. It may be noted that in the family history of two patients (2 and 3) there was a history of a depression of religious content, in case 2 the mother, in case 3 the sister. A history of obsessional illness was found in the family of the third patient.

Ecstasies differ from manic states. The essential nature of the ecstatic state lies in the remarkable pantheistic experience of the subject that he and the universe are one, associated with a mood which is quite peculiar and qualitatively different from that of mania. This mood is peaceful and tranquil, in marked contrast to mania. The difference between the two states was seen most clearly in the first patient, who, following a typical but mild hypomanic state, passed into the ecstasy and became less active, quieter, at peace with herself and everybody else. The paranoid features, usually intensified in mania, disappeared. Again in the third patient there was no pressure of thought, but she became rather more active than before. In the last patient there was happy tranquillity, in contrast to anything usually found in a manic state. The third case shows therefore that immobility is not an essential feature of these states, as Janet thinks, though there does exist a tendency in some states of ecstasy to a reduction of motor activity, as in case 1. It is possible that the decreased restlessness of this patient was merely a step towards a condition in which immobility was complete. With regard to the question of decreased motor activity, there is one condition, namely manic stupor, to bear in mind in considering the relationships of these states to others found in manic-depressive illness. It might well be that there is a relationship between manic stupor and the more extreme form of ecstasy. A study of Janet's case brings this to mind. Both manic stupor and ecstasy of the kind discussed here are rare. A difference between these two conditions is that in manic stupor there is usually " retardation " of thought and in the ecstasy an exuberant productivity. In Janet's case there was no flight of ideas. Those patients who in their stupor had a flight of ideas described this retrospectively, and did not refer to anything in the 
nature of an ecstasy. It is not suggested that Janet's patient Madeleine presented a manic stupor, but a state more akin to hypnosis as evidenced, inter alia, by her heightened suggestibility. But Janet states that ecstatics should not be confused with somnambulists, whose mind is void and who have only one idea, that of obedience to the hypnotist. Further work on this problem of the possible relationship to manic stupor seems desirable.

The exalted manic who claims prophetic powers is familiar. This feature may be an expression of the increased feeling of power, but may also depend on the presence of a slight degree of that alteration of consciousness which characterizes ecstasy, just as in some depressives there are slight degrees of depersonalization which would pass unobserved unless careful scrutiny were made. The increased feeling of power also arises out of the peculiar affect"Glücksaffekt"-as Mayer-Gross shows. Schou (1926) describes a case of manic-depressive psychosis in which the patient claimed to have been given special insight into the meaning of the Bible, which he felt he could interpret more clearly. Similar examples are common. The increased perception of detail may also be mentioned, although distractibility is absent. There is a difference in retrospective attitude of the manic and ecstatic patient. The manic patient regards his experience as something painful and to be forgotten. It is otherwise with the ecstatic patient, who often longs for the recurrence of the state of bliss, which he interprets as a rich spiritual experience and which may have a permanent effect on the personality. Jaspers quotes Gérard de Nerval as illustrating this attitude to mystical experiences. He goes on to say that this assimilation into the personality is predominantly but not exclusively the case in schizophrenic psychoses.

Janet shows the effect of his patient Madeleine's ecstatic experiences on her personality and how her subsequent attitude to the environment was changed" the hospital was marvellous," "all the patients have features of a ravishing and angelic beauty, all the staff are so good to her, she has no difficulty with anybody." The difference in subsequent insight is probably not dependent on the mood alone. If it were, the retrospective attitude to a mania and an ecstasy might be expected to be the same. It is not dependent on the feeling of power, which is a feature of both. Janet interprets the attitude of the patient to the ecstasy on the basis that we associate sadness and misery with sickness, joy with well-being and success, and adds that it is necessary to understand that joy is not always reasonable. In writing so he addresses himself to the religious interpreters of ecstasy and not to psychiatrists. With reference to the influence of the conversion experience on the religious life, the character and personality of the individual are essential factors in determining how such states once experienced are interpreted by the subject. The intensity of the experience may also be a factor.

Starbuck $(1909$, p. 384$)$ believed that the conversion experience brought about " a changed attitude towards life, which is fairly constant and permanent, although the feelings fluctuate. . . " This is only true of some cases. I have recently seen two schizophrenics who had ecstatic or ecstasy-like experiences. One, a woman of 34 , just before passing into a typical catatonic stupor, described 
how two years previously she had become " changed" as the result of a " power outside herself." She felt " lighter" and the burden of sin was removed. She described it as " a nebulous idea of conscience, like a voice in the room, not necessarily conscience, but more directive than conscience." She heard the voice in her mind not in her ears, partly subjective, partly objective. She spoke of it as a " revelation." The other, a man of 34, who in the acute stages of his illness saw angels flying above the streets, the Devil in the form of sharks leaping from hedges, etc., described several " experiences of the Inner Light," as he termed them, which occurred during this period. Thus after animated discussion on religion one evening he returned home tired and lay on his bed. "The room became suffused with light (the electric light was on, but this was a spiritual not a natural light), enhancing the colours of the fabrics, etc. I was filled with a warmth and glow and a sense I was not alone." He had a similar experience after sending a religious tract to a sick woman he had heard of. $\mathrm{He}$ felt he might have been impertinent in this. "That same evening the 'light" experience took place bringing conviction that this woman and I were mystically united in Heaven, and that what I had done was meeting with Heaven's approval." These experiences are different from those already described, though the passivity, intuitions, and sense of a greater power are present in all. These features of the ecstasy, however, are given characteristically schizophrenic mould and just as depersonalization occurs in different forms of mental disorder, so may ecstatic features, although it is doubtful if they ever take the form in schizophrenia which is found in the disorders under discussion here.

The relationship of other components of the morbid picture to ecstasy states may be mentioned. As already seen, three of the patients (2, 3, and 4) presented definite hysterical features. In Janet's case they were prominent, and it is assumed, probably too readily and on insufficient evidence, that all the noted mystics were hysterics. The question arises how far ecstatic states of the kind here described can arise on an hysterical basis alone, and how far on a manicdepressive alone. This is not easy to answer and can only be done on the basis of personally observed data. That a poor organization of the ego function is a feature of hysteria is admitted, and many of our most striking examples of depersonalization, such as micropsia, are found in hysterics without any notable degree of depression, though this last factor is often difficult to assess. Most, if not all of the examples of glossolalia and inspired writing occur in hysterics. The infectious religious movements almost certainly contain a notable proportion of such psychopaths, even allowing for mass suggestibility. That there is a relationship between the poorly integrated hysterical ego and ecstasy in at least some cases is undoubted, but it may be that as depersonalization is not peculiar to hysteria, neither is ecstasy. Certainly some of the more modern recorded experiences of " cosmic consciousness" do not appear to have involved hysterical personalities. The small total of psychiatrically observed material, however, makes conclusions impossible. The ecstasy may be related to the type of depersonalization occurring in obsessionals. Janet described Madeleine as a "scrupulous obsessional." Crichton-Browne reported a case in which attacks of loss of identity occurred after ruminations on such questions as 
"Who am I ?" "What am I ?" etc. Obsessional features were found, notably in cases 1 and 3, but were not present in the other two. Janet (1903) sees a relationship between the two states and comments on the frequency with which he has found "sublime and solemn emotions" in these patients. On all these problems further work is required.

The third patient gave the most explicit information as to the circumstances in which the state arose. She had just been parted from her lover. Following this a period of painful tension of a peculiar kind arose and developed into the ecstasy. Those using dynamic interpretations will regard this as a compensation, a wish-fulfilment. Such a causal explanation cannot be invoked for her other ecstasies. In the second patient the ecstasy followed a period in which sense of guilt was strong. Janet regards these as reactions to a state produced by regression and withdrawal, and says : " they can in certain cases play the rôle of a defensive reaction which favours the gathering up again of forces and permitting later more complete action." Bleuler regards the ecstasy as the achievement of the maximum of wish-fulfilment. These states correspond to the obverse of the medal of which depersonalization is the reverse. Lastly, the age of the patient deserves consideration. None of the first three exceeded 30 years. The fourth, who is not directly comparable to the others, was 39 . Manic states also tend to be more frequent in earlier life. With regard to conversion experiences, Starbuck (1909), as the result of a statistical enquiry, demonstrated that the large majority of religious conversions took place between the ages of 12 and 25 years. The first patient here was 24 , the second 23, and the third 21 years when the ecstasy first appeared. It may also be noted that J. A. Symonds found these states recurred in him with diminishing frequency to the age of 28 .

\section{Summary}

Four cases of affective disorder have been recorded in which ecstasy states occurred as phases. These cases have been recorded because little psychiatric study has been devoted to such cases owing to their comparative rarity. An attempt has been made to show the relationship of these states of ecstasy to affective disorders. The features in which the states described here resemble and differ from mania have been discussed. The characteristic manic mood differs widely from that found in ecstasy. The latter state comprised a sense of inner tranquillity and peace, a feeling of harmony with the environment, and in one case a reduction of motor activity in contrast with the previous hypomanic condition, and the paranoid attitude, which in this latter state had been prominent, disappeared. This reduction of motor activity also occurred in two other cases ; in the remaining case it seemed to be increased.

A difference in retrospective attitude towards the manic and ecstatic state was also observed, as well as the different effect caused by these states on the subsequent personality. A possible relationship between ecstasy and manic stupor is suggested and the desirability of further work on this problem indicated. 
The relationship of other components of the morbid picture, the hysterical and obsessional, has been considered, but no conclusion has been reached. The difference between the ecstasies described here and those found in schizophrenia has also been briefly mentioned. Previous psychiatric observations on ecstasy have been discussed and criticized. The clinical features and the differential diagnosis have been discussed. A psychological causal interpretation of these states was not possible-a conclusion in agreement with Rümke (1924).

\section{REFERENCES}

Alexander, F. (1931). Psycho-anal. Rev., 18, 129.

Bleuler, E. (1924). Text Book of Psychiatry (Trans. Brill). Macmillan, London.

Brown, H. F. (1895). John Addington Symonds. A Biography compiled from his Papers and Correspondence. (Quoted James, op. cit.)

Bucke, R. M. (1901). Cosmic Consciousness : A Study in the Evolution of the Human Mind. Philadelphia, Pa. (Quoted James, op. cit., p. 398.)

Bumke, O. (1929). Lehrbuch der Geisteskrankheiten. 3rd edition, Munich.

Carpenter, E. (1919). The Art of Creation. 4th edition, London.

Crichton-Browne, J. (1895). Lancet, 2, 73.

Flouroy, T. (1915). Arch. Psychol. Genève, 15, 1.

Geiger, M. (1911). Z. Asthetik allg. Kunstwissenschaft, 6, 1.

Gruhle, H. (1922). Psychologie des Abnormen. Kafta's Handbuch der vergleichenden Psychologie, 3, 1, 77.

James, W. (1908). Varieties of Religious Experience. 16th imp., London.

Jaspers, K. (1923). Allgemeine Psychopathologie. 3rd edition, Berlin.

Janet, P. (1903). Les Obsessions et la Psychasthénie. Paris.

Janet, P. (1926-28). L'Angoisse à l'Extase. Paris.

Kleist, K. (1928). Schweiz. Arch. Neurol. Psychiat., 23, 1, 3.

Lévy-Bruhl, L. (1921). Das Denken der Naturvölker. Vienna and Leipzig.

Mayer-Gross, W. (1914). Zur Phenomenologie abnormer Glücksgefühle. Leipzig and Berlin. Mondain, P. (1923). Les Fous Satisfaits. Paris.

Rümke, H. C. (1924). Zur Phenomenologie und Klinik der Glücksgefühle. (Gesamtgebiet Neurol. Psychiat, 39, Berlin.)

Schou, H. J. (1926). Religiosity and Morbid Mental States. Methuen, London.

Starbuck, E. D. (1909). Religionspsychologie (Trans. F. Bata). Leipzig.

Thouless, R. H. (1923). An Introduction to the Psychology of Religion. Cambridge.

Trine, R. W. (1897). In Tune with the Infinite. (Quoted James.)

Zucker, K. (1934). Z. ges. Neurol. Psychiat., 150, 693. 